\title{
Dretske on self-knowledge and contrastive focus: How to understand Dretske's theory, and why it matters
}

Michael Roche* and William Roche $\dagger$

* Department of Philosophy, Mississippi State University, MS, USA, e-mail: mjr454@msstate.edu

$†$ Department of Philosophy, Texas Christian University, TX, USA, e-mail: w.roche@tcu.edu

ABSTRACT: Dretske's theory of self-knowledge is interesting but peculiar and can seem implausible. He denies that we can know by introspection that we have thoughts, feelings, and experiences. But he allows that we can know by introspection what we think, feel, and experience. We consider two puzzles. The first puzzle, PUZZLE 1, is interpretive. Is there a way of understanding Dretske's theory on which the (potential) knowledge affirmed by its positive side is different than the (potential) knowledge denied by its negative side? The second puzzle, PUZZLE 2, is substantive. Each of the following theses has some prima facie plausibility: (a) there is introspective knowledge of thoughts, (b) knowledge requires evidence, and (c) there are no experiences of thoughts. It is unclear, though, that these claims form a consistent set. These puzzles are not unrelated. Dretske's theory of self-knowledge is a potential solution to PUZZLE 2 in that if Dretske's theory is correct, then (a), (b), and (c) are all true. We provide a solution to PUZZLE 1 by appeal to Dretske's early work in the philosophy of language on contrastive focus. We then distinguish between "Closure" and "Transmissibility", and raise and answer a worry to the effect that Dretske's theory of self-knowledge runs counter to Transmissibility. These results help to secure Dretske's theory as a viable solution to PUZZLE 2.

KEYWORDS: closure; contrastive focus; contrastivist theories of knowledge; Dretske; introspection; introspective knowledge; self-knowledge; transmissibility 


\section{Introduction}

Dretske's theory of self-knowledge (2012a) is interesting but peculiar and can seem implausible. ${ }^{1}$ Dretske admits that he himself many years ago would have thought the theory implausible:

I have lately ... been advancing a view about self-knowledge that forty years ago I would have thought implausible. ... I defend it because over these years I have developed commitments - all of which seem reasonable to me - that lead, irresistibly, to the conclusion that although we have direct awareness of and, therefore, a unique authority about what is in our mind and about what we think, feel, and experience, we enjoy no special access to or authority about the fact that we have a mind - to the fact that we actually have thoughts, feelings, and experiences. (2012a, p. 49, emphasis original)

He denies that we can know by introspection - an essentially first-personal way (a way not available to others) - that we have thoughts, feelings, and experiences. ${ }^{2}$ But he allows that we can know by introspection what we think, feel, and experience. He calls his theory "conciliatory skepticism". 3

There is mention of experiences and feelings in the passage above. But Dretske later restricts attention to (current conscious) thoughts understood as non-factive propositional attitudes where the propositions involved are accepted as true. Beliefs and judgments count as thoughts in this sense whereas hopes and rememberings do not. ${ }^{4}$ Our focus in what follows will likewise be on thoughts (so understood).

It will help in discussing Dretske's theory to formulate it in terms of a schematic case:

${ }^{1}$ Dretske's writings on self-knowledge are numerous. See Dretske (1994, 1995, 1999, 2003a, 2003b, 2003c, 2006b, 2011, 2012a, 2012b, 2012c). Dretske (2012a) is representative of Dretske's later writings on self-knowledge and, in part because of this, is our main focus in explaining his theory.

${ }^{2}$ Dretske allows that we can know non-introspectively that we have thoughts, feelings, and experiences.

${ }^{3}$ The extant literature on introspection and self-knowledge is vast. See Gertler (2014) and Schwitzgebel (2014) for helpful overviews (and for references). See also Smithies and Stoljar (2012).

${ }^{4}$ Dretske claims that he limits the discussion to thoughts only for expository purposes and that his arguments concerning thoughts can be generalized (with some complication) to non-thoughts. Dretske refers readers to Dretske (2003b) for details. 
Dretske on Self-Knowledge (DSK): Let $\mathrm{S}$ be some subject and $\mathrm{P}$ be some proposition such that $\mathrm{S}$ thinks that $\mathrm{P}$. Then $\mathrm{S}$ knows, or at least can know, by introspection what she thinks, but does not know, and cannot know, by introspection that she thinks it.

Note that there is no mention of "P" in the second sentence of DSK. The reason why is that there is no straightforward and charitable way to flesh out that sentence in terms of "P". It might be thought, for example, that since $\mathrm{P}$ is what $\mathrm{S}$ thinks, the second sentence of DSK should read:

Then S knows, or at least can know, by introspection [that P], but does not know, and cannot know, by introspection that she thinks [that P].

But this interpretation is widly uncharitable, for there are numerous substitutions for $\mathrm{P}$ (e.g., the Earth revolves around the Sun) such that $\mathrm{S}$ cannot know by introspection that $\mathrm{P}$. A main task in the remainder of the paper is to make clear how exactly DSK is to be understood.

Hereafter we shall omit the expression "or at least can know" and suppose that the details of the case are such that Dretske would claim that $\mathrm{S}$ knows by introspection what she thinks. This is merely a matter of presentation.

What, for Dretske, is the source of S's introspective knowledge of what she thinks? Dretske's answer is that the source is S's awareness of what she thinks. S's awareness is a non-epistemic awareness of an object (albeit an abstract object), viz., the proposition that $\mathrm{P}$, as opposed to an epistemic awareness of $a$ fact, i.e., a piece of propositional knowledge. That is, the source of S's introspective knowledge of what she thinks is an "o-awareness" ("object-awareness") as opposed to an "f-awareness" ("fact-awareness"). 5

It is crucial here to distinguish between the source of S's introspective knowledge and the content of S's introspective knowledge. The source of the introspective knowledge allowed by DSK is not in question - it is S's o-awareness of P. Dretske is clear on this point. The content of that knowledge is a different story (to say the least!) and, as explained below, is the subject of an interpretive puzzle.

Dretske gives an analogy meant to make clear the structure of self-knowledge on his thoery:

The Philosophical Gazette, smitten with my deep thoughts, arranges to publish everything I write. They give me oral assurances of this, and (let us assume) their word is gold. On the basis of their assurances, then, I know they publish everything I write. I now write [P]. The Gazette promptly publishes it. Given what I have been told, I know they are publishing $[\mathrm{P}]$. Yet the way I know what they are publishing is not the way I know they are publishing it. (2012a, p. 54, emphasis original)

${ }^{5}$ See Dretske (2012b) for more on the distinction between o-awareness and f-awareness. 
The source of Dretske's knowledge of what PG (the Philosophical Gazette) is publishing is not the source of his knowledge that PG is publishing it. The source of the former is Dretske's o-awareness of what he wrote; the source of the latter is (Dretske's knowledge of) PG's promise. Similarly, the idea goes, S's o-awareness of what she thinks (viz., the proposition that $\mathrm{P}$ ) is the source of her knowledge of what she thinks but is not the source of her knowledge that she thinks it.

It might seem that there is a relevant disanalogy between the two cases. When Dretske is o-aware of what he wrote, he is not also o-aware of PG's publishing it. It might seem that, in contrast, when $\mathrm{S}$ is o-aware of the proposition that $\mathrm{P}$, she is also oaware of her thinking it. If so, then, it might seem, S cannot know by introspection what she thinks without also knowing (or at least being able to know) by introspection that she thinks it.

Dretske (2012b) explicitly considers this line of thought. He rejects it in part on the grounds that, as far as he can tell, there are no o-awarenesses of thoughts (or, thus, of thinkings). ${ }^{6} \mathrm{He}$ also argues that even if $\mathrm{S}$ were o-aware of her thought that $\mathrm{P}$, this by itself would not be enough. She would also need to be o-aware of a property of her thought indicating that it is a thought. ${ }^{7}$

Given Dretske's rejection of o-awarenesses of thoughts, there is a clear sense in which, if Dretske is right, introspective knowledge of thoughts is a species of "displaced perception" broadly understood. S knows by introspection what she thinks, not by way of an o-awareness of her thought that $\mathrm{P}$, but by way of an o-awareness of something else entirely. ${ }^{8}$

There is a puzzle, though, as hinted at above, concerning how exactly to understand DSK. It is widely held in epistemology (and elsewhere) that knowledge-what reduces to knowledge-that. ${ }^{9}$ Consider:

${ }^{6}$ Dretske (2003b) also holds that there are no o-awarenesses of experiences and refers readers to Shoemaker (1994) for details as to why.

${ }^{7}$ This requirement is far from trivial if certain externalist theories are correct. See Lau and Deutsch (2014) and Parent (2013) for relevant discussion.

${ }^{8}$ Dretske writes in terms of "displaced perception" in his early work on self-knowledge (Dretske 1994; 1995, Ch. 2). There, though, he has in mind a narrower understanding of displaced perception on which displaced perception requires "connecting beliefs". See Aydede (2003), Kemmerling (1999), and Lycan (2003) for critical discussion. Dretske drops all reference to "displaced perception" in his subsequent work on self-knowledge. This could be because of a change in view. It could instead be because of a change in strategy. The important point, though, for our purposes, is that even in his later work he rejects o-awarenesses of thoughts and thus holds that $S$ 's introspective knowledge of what she thinks is due, not to an o-awareness of her thought that $\mathrm{P}$, but to an o-awareness of something else entirely.

${ }^{9}$ See Schaffer (2007, sec. 1) for helpful discussion. 
Reductivism on Knowledge-What (RKW): $\mathrm{S}$ knows what $\mathrm{X}$ if and only if there is a proposition P such that (a) S knows that P and (b) "P" is the correct answer to the indirect question referred to by the expression "what X".

The correct answer, it seems, to the indirect question referred to by the expression "what she thinks" is "S thinks that P". If so, and supposing that RKW is correct, then S knows by introspection what she thinks if and only if $\mathrm{S}$ knows by introspection that she thinks that $\mathrm{P} .{ }^{10}$ But then how could it be that, as per DSK, S knows by introspection what she thinks and yet does not know by introspection that she thinks it?

It might be suggested that the correct answer to the indirect question referred to by the expression "what she thinks" is simply "P". But if that suggestion were accepted and generalized to other cases, then RKW would be highly implausible. Suppose (taking a case from Schaffer 2007, p. 386) that the time is 6:00 pm. Does S know what time it is? If the suggestion were accepted and generalized to other cases, then, regardless of S's evidence, the answer would be no. This is because it cannot be known that 6:00 pm (for " $6: 00 \mathrm{pm}$ " is not a proposition). The right way to understand RKW in this case is such that the correct answer to the indirect question about the time is "the time is 6:00 pm". Similarly, the right way to understand RKW in the case of S and her thought that $\mathrm{P}$ is such that the correct answer to the indirect question about her thought is " $\mathrm{S}$ thinks that P".

It is unclear, then, whether there is a way of understanding DSK on which the introspective knowledge affirmed by its positive side (the proposition $\mathrm{S}$ is said to know by introspection) is different than the introspective knowledge denied by its negative side (the proposition $\mathrm{S}$ is said to not know by introspection). We call this "PUZZLE 1".

There is a second puzzle. Consider:

Introspective Knowledge (IK): $\mathrm{S}$ has introspective knowledge concerning her thought that $\mathrm{P}$.

Knowledge Requires Evidence (KRE): Knowledge requires evidence in that $\mathrm{S}$ knows that $\mathrm{P}$ only if $\mathrm{S}$ has evidence $\mathrm{E}$ such that $\mathrm{E}$ indicates that $\mathrm{P}$.

No Inner Experiences (NIE): S has no o-awareness of her thought that P.

Each of these theses has some prima facie plausibility (to say the least). It is unclear, though, that they can all be true. Suppose KRE and NIE are true. By KRE it follows that

\footnotetext{
${ }^{10} \mathrm{We}$ are assuming, as is plausible, that RKW should be understood so that $\mathrm{S}$ knows by $a$ certain way what $\mathrm{X}$ if and only if there is a proposition $\mathrm{P}$ such that (a) $\mathrm{S}$ knows by that way that $\mathrm{P}$ and (b) $\mathrm{P}$ is the correct answer to the indirect question referred to by the expression "what $\mathrm{X}$ ".
} 
$\mathrm{S}$ knows that she thinks that $\mathrm{P}$ only if she has evidence $\mathrm{E}$ such that $\mathrm{E}$ indicates that she thinks that P. By NIE it follows that S has no o-awareness of her thought that P. But then, the worry goes, $\mathrm{S}$ has no introspective evidence - essentially first-personal evidenceconcerning her thought that $\mathrm{P}$ and thus, by KRE, has no introspective knowledge concerning her thought that $P$. This, though, would make IK false. This is "PUZZLE 2".

A growing number of philosophers working on self-knowledge reject KRE when it comes to self-knowledge. ${ }^{11}$ It might be that this is ultimately the right response to PUZZLE 2. It would be interesting, though, if there were a way for one to consistently accept KRE along with IK and NIE.

PUZZLE 1 is interpretive whereas PUZZLE 2 is not. The two puzzles, though, are not unrelated. DSK is a potential solution to PUZZLE 2. Dretske accepts each of IK, KRE, and NIE. ${ }^{12}$ DSK is meant to show how they can all be true. $\mathrm{S}$ knows by introspection what she thinks. Thus IK is true. ${ }^{13}$ But $\mathrm{S}$ does not know by introspection that she thinks it. This is because KRE and NIE are true. Anyone interested in PUZZLE 2 should thus also be interested in DSK and, in turn, PUZZLE 1.

DSK has been largely neglected in the literature. ${ }^{14} \mathrm{We}$ suspect that a main reason for this is that philosophers working on self-knowledge see no way of solving PUZZLE 1. We aim to rectify the situation by, in part, providing a solution to PUZZLE 1. We do so

${ }^{11}$ See Roche and Roche (2016) for discussion.

${ }^{12}$ It might be thought that Dretske rejects KRE, given his endorsement of reliabilism. But while Dretske takes himself to be a reliabilist of sorts, he stresses that he is not a process reliabilist. See Dretske (2003b, pp. 11-12, n. 15, 2012a, p. 51, n. 3). His epistemology is evidence-based (though he oftentimes speaks in terms of reasons as opposed to evidence). Dretske's writings on knowledge are extensive. See, e.g., Dretske (1969, 1970, 1971, 1975, 1981a, 1981b, 1991, 2005a, 2005b).

${ }^{13}$ Recall that, for Dretske, the source of S's knowledge of what she thinks is S's oawareness of the proposition that P. Given that others can be o-aware of $\mathrm{P}$, how is S's knowledge of what she thinks introspective (in the sense defined above)? Dretske's view is that subjects other than S cannot come to know what $S$ thinks by coming to be o-aware of the proposition that $\mathrm{P}$.

${ }^{14}$ The claim here is not that Dretske's work on self-knowledge has been largely neglected in the literature. It has not (see, for example, Aydede 2003, Byrne 2012, Kemmerling 1999, Lycan 1999, and Stoljar 2012). The claim, rather, is that DSK in particular - the thesis that $\mathrm{S}$ knows by introspection what she thinks but does not know by introspection that she thinks it - has been largely neglected in the literature. Lycan (2003, secs. 4 and 5) discusses it but only briefly. 
by appeal to Dretske's early work in the philosophy of language on contrastive focus (1972). ${ }^{15}$

The remainder of the paper is organized as follows. In Section 2, we explain Dretske's work on contrastive focus. In Section 3, drawing on the discussion in Section 2, we set out our solution to PUZZLE 1. In Section 4, we return to PUZZLE 2. We distinguish between "Closure" and "Transmissiblity" and explain a worry to the effect that DSK should be rejected because it runs counter to Transmissibility. We attempt to answer that worry on Dretske's behalf, thereby securing DSK as a potential solution to PUZZLE 2. In Section 5, we conclude.

\section{Dretske on contrastive focus}

Consider the expressions:

(1a) Clyde lent Alex $\$ 300$.

(1b) Clyde lent Alex $\$ 300$.

(1c) Clyde lent Alex $\$ 300$.

(1d) Clyde lent Alex $\$ 300$.

Each of these expressions stands in contrast to:

(1e) It is not the case that Clyde lent Alex $\$ 300$.

But, as indicated by underlining, they differ in contrastive focus and thus in highlighted (or featured) contrasts. Take (a) for example. The contrastive focus is the amount of money lent and the highlighted contrast is between $\$ 300$ and, say, $\$ 500$. Dretske (1972) calls expressions such as (1a)-(1d) "contrastive statements". ${ }^{16}$

It is not implausible prima facie that there are cases where it would be appropriate to utter (using intonation) one of (1a)-(1d) but not the others. Suppose Clyde tells you that he lent Alex $\$ 300$. Suppose your friend, though, is under the impression that Clyde lent

\footnotetext{
${ }^{15}$ Lycan (2003, p. 27, n. 6) notes in passing that Dretske (1972) might be helpful in understanding Dretske's work on self-knowledge. If our solution to PUZZLE 1 is correct, then Dretske (1972) is in fact helpful to that end.

${ }^{16}$ Elsewhere Dretske $(1975,1977)$ refers to expressions such as (1a)-(1d) as "propositional allomorphs".
} 
Alex \$500. Then, since your friend's mistake concerns just the amount of money lent, it would be appropriate for you to utter (1a) but not (1b), (1c), or (1d).

Do expressions such as (1a)-(1d) differ in meaning? Dretske (1972, sec. II) answers in the negative. They are composed of the same words with the same meanings in the same order and are about the same things. They differ merely pragmatically.

Dretske, though, argues that expressions such as (1a)-(1d) can nonetheless make for a difference in meaning when embedded in larger contexts, that is, when they are parts of larger expressions. He gives several examples to illustrate. It will prove helpful to consider three of them in some detail.

The first example involves the context “... advised ...” (Dretske 1972, pp. 415-417). Suppose:

Clyde owns a 1927 Lincoln that is in mint condition and Schultz offers him \$30,000 for it. Clyde asks Alex for his advice on the matter. Alex advises Clyde to sell the car to Schultz, claiming that it is not likely that the car will become more valuable and that he might never again receive such a fine offer for it. Clyde takes Alex's advice and sells his car to Schultz. But then Schultz skips town and his check bounces.

Consider the expressions:

(4a) Alex advised Clyde to sell his car to Schultz for $\$ 30,000$.

(4b) Alex advised Clyde to sell his car to Schultz for $\$ 30,000$.

Dretske claims that (4a) is true whereas (4b) is false and that, thus, (4a) and (4b) differ in meaning. Alex's advice concerned the fairness of the price, not the trustworthiness of the purchaser. ${ }^{17}$ He further claims that this difference in meaning is due to the difference in contrastive focus between the embedded expressions "to sell his car to Schultz for $\$ 30,000 "$ " and "to sell his car to Schultz for $\$ 30,000$ ".

The second example involves the context “... reason ..." (Dretske 1972, pp. 417418). Suppose:

Clyde is a bachelor and very much wants to maintain his bachelor lifestyle. He learns, though, that he will inherit a great deal of money if he is married by the age of thirty. He looks around and finds Bertha. She is an archaeologist and spends eleven months

${ }^{17}$ It might seem that (4b) would be true if the details were such that Clyde also received an offer from Herb for $\$ 20,000$ and Alex knew this. It can be stipulated, though, that the details are such that Clyde received just one offer (the one from Schultz) and Alex knows this. 
each year abroad directing excavations. Clyde proposes to Bertha, she accepts, and they get married.

Consider the expressions:

(5a) The reason Clyde married Bertha was to qualify for the inheritance.

(5b) The reason Clyde married Bertha was to qualify for the inheritance.

Dretske claims that (5a) is false whereas (5b) is true and that, thus, $(5 a)$ and $(5 b)$ differ in meaning. The reason Clyde got married was to qualify for the inheritance, but the reason he chose Bertha was to maintain as much as possible his bachelor lifestyle. He further claims that the difference in meaning between (5a) and (5b) is due to the difference in contrastive focus between the embedded expressions "Clyde married Bertha" and "Clyde married Bertha".

The third, and final, example involves the context “... because ...” (Dretske 1972, pp. 419-420). Suppose:

Alex loses his job and needs some money to meet expenses until he finds a new job. Clyde believes that Alex needs $\$ 300$ and so lends him that amount.

Consider the expressions:

(6a) Clyde lent Alex $\$ 300$ because that is how much money he thought Alex needed.

(6b) Clyde lent Alex $\$ 300$ because that is how much money he thought Alex needed.

Dretske never explicitly considers these expressions. But he does claim that the question of why Clyde lent Alex $\$ 300$ and the question of why Clyde lent Alex $\$ 300$ are distinct and admit of different answers (or at least would on certain ways of filling in the details), given the difference in contrastive focus. It is thus clear that he would claim that (6a) and (6b) differ in meaning due to a difference in contrastive focus. ${ }^{18}$

${ }^{18}$ Dretske holds not just that explanatory contexts are sensitive to differences in contrastive focus but also that causal contexts are sensitive to differences in contrastive focus. See Dretske (1977) for discussion. There is a growing literature on the issue of whether causal/explanatory contexts are sensitive to differences is contrastive focus. See Schaffer (2005b) for discussion and for further references. 
These examples have some force. We grant for the sake of argument that expressions such as (1a)-(1d) can make for a difference in meaning when embedded in larger contexts. In the remainder of this section we consider exactly how, for Dretske, this is so.

Dretske's comments on his three examples are helpful on this front. Regarding the first example he writes:

We can express this by saying that the scope of the "advice" operator is determined by the contrastive contour of the operand; the advice must be understood in reference to the contrastive focus (or foci) of the advice's content. (1972, p. 416)

Regarding the second example he writes:

Reasons of the sort we are now considering provide a justification (of sorts) and sometimes an explanation, not for everything that is involved in the expression of what one has a reason for doing, but only for that which constitutes the contrastive focus of what one has a reason for doing. (1972, p. 418, emphasis original) Regarding the third example he writes:

In a context in which "Clyde" constitutes the contrastive focus of our explanandum, explanations are explanations of why Clyde, rather than someone else, did what Clyde did. When what Clyde did is the focus, explanations are explanations of why Clyde did that rather than something else. (1972, p. 420, emphasis original)

We read Dretske as follows:

Dretske on Contrastive Focus (DCF): For any context $\mathrm{C}$, if $\mathrm{C}$ is sensitive to differences in contrastive focus, then this is because (a) $\mathrm{C}$ involves an operator $\mathrm{O}$, (b) $\mathrm{O}$ is sensitive to differences in what alternatives are relevant, and (c) what alternatives are relevant is sensitive to differences in contrastive focus.

Dretske is never this explicit on the workings of contrastive focus. But since DCF fits well with his comments on his three examples (along with his comments on his other examples), and since DCF has some plausibility in itself, we put it forward as a charitable reading of Dretske on contrastive focus.

Dretske's examples make a lot of sense when understood in terms of DCF. Take his third example for instance. The contrastive focus in "Clyde lent Alex $\$ 300$ " serves to determine that the scope of the operator "because" in (6a) is restricted to the amount of money that Clyde lent Alex, so that the only relevant alternatives are, say, the following:

(a1) Clyde lent Alex \$300. 

Clyde lent Alex $\$ 500$.

This can be brought out by reformulating (6a) as:

(6a*) Clyde lent Alex $\$ 300$ rather than $\$ 500$ because that is how much money he thought Alex needed.

The contrastive focus in "Clyde lent Alex \$300", in turn, serves to determine that the scope of the operator "because" in $(6 \mathrm{~b})$ is restricted to the nature of the transaction between Clyde and Alex, so that the only relevant alternatives are, say, the following:

(a1) Clyde lent Alex $\$ 300$.

(a3) Clyde gave Alex \$300.

This can be brought out by reformulating (6b) as:

(6b*) Clyde lent rather than gave Alex $\$ 300$ because that is how much money he thought Alex needed.

It is not implausible that $\left(6 a^{*}\right)$ is true while $\left(6 b^{*}\right)$ is false. It is thus not implausible that, as Dretske claims, (6a) and (6b) differ in meaning despite the fact that the embedded expressions "Clyde lent Alex $\$ 300 "$ and "Clyde lent Alex \$300" are the same in meaning. 19

There is an alternative way of reformulating (6a) and (6b). Consider:

$\left(6 \mathrm{a}^{* *}\right) \quad$ Given that (or on the understanding that) either Clyde lent Alex $\$ 300$ or Clyde lent Alex $\$ 500$ (but not both), Clyde lent Alex $\$ 300$ because that is how much money he thought Alex needed.

$\left(6 b^{* *}\right) \quad$ Given that (or on the understanding that) either Clyde lent Alex $\$ 300$ or Clyde gave Alex $\$ 300$ (but not both), Clyde lent Alex $\$ 300$ because that is how much money he thought Alex needed.

${ }^{19}$ While contrastive focus sometimes determines the scope of an operator, it never by itself determines which alternatives are relevant. For example, while the contrastive focus in "Clyde lent Alex \$300" determines that the scope of the operator "because" in (6a) is restricted to the amount of money that Clyde lent Alex, it does not determine which alternatives to (a1) are relevant. So what does? This is a difficult question. Fortunately, though, how exactly it is to be answered is not important for our purposes, and so shall be set aside. But see Dretske (1981b, pp. 373-378) for discussion. 
Neither $\left(6 \mathrm{a}^{* *}\right)$ nor $\left(6 \mathrm{~b}^{* *}\right)$ involves the expression "rather than". But with $\left(6 \mathrm{a}^{* *}\right)$, as with $\left(6 \mathrm{a}^{*}\right)$, the relevant alternatives are restricted to (a1) and (a2), and with $\left(6 \mathrm{~b}^{* *}\right)$, as with $\left(6 b^{*}\right)$, the relevant alternatives are restricted to (a1) and (a3). So, for our purposes, $\left(6 \mathrm{a}^{* *}\right)$ and $\left(6 b^{* *}\right)$ are equivalent to $\left(6 \mathrm{a}^{*}\right)$ and $\left(6 \mathrm{~b}^{*}\right)$, respectively.

We mention this because Dretske sometimes speaks along the lines of $\left(6 \mathrm{a}^{* *}\right)$ and $\left(6 \mathrm{~b}^{* *}\right) .{ }^{20}$ We take the passages in question to count in favor of, not against, DCF as a reading of Dretske on contrastive focus.

We return now to PUZZLE 1.

\section{A solution to PUZZLE 1}

Dretske (1972) argues that the context "... knows that ...", as with the contexts “... advised ...", "the reason ... was to ...", and "... because ...", is sensitive to differences in contrastive focus. Consider the expressions:

(7a) Alex knows that Clyde married Bertha.

(7b) Alex knows that Clyde married Bertha.

Dretske gives a case, where in fact Clyde married Bertha, meant to show that (7a) and (7b) can differ in truth-value and that, thus, they differ in meaning. He writes:

Alex has strong evidence to support the claim that Clyde's betrothed is the local chairwoman of the Women's Liberation Movement; he also has strong evidence to support the claim that Bertha is the local chairwoman. This is his evidence to support the claim that Clyde married Bertha. His justification for thinking that Clyde married Bertha is that Clyde could not have collected the inheritance unless he married her and Alex knows that Clyde collected the inheritance. If, now, we suppose that Bertha is not the local chairwoman of the Women's Liberation Movement and that Clyde did not marry the local chairwoman (despite Alex's strong evidence in favor of both), we have a situation in which, although Alex does not know that Clyde married Bertha, he does know that he married Bertha. (1972, p. 436, emphasis original)

How are (7a) and (7b) to be understood?

The answer (drawing on DCF) is clear. The contrastive focus in "Clyde married Bertha" serves to determine that the scope of the operator "knows" in (7a) is restricted to the identity of the person Clyde married, so that the only relevant alternatives are, say, the following:

${ }^{20}$ See Dretske (1972, p. 433). 
(a4) Clyde married Bertha.

(a5) Clyde married Beatrice.

This can be brought out by reformulating (7a) as:

(7a*) Alex knows that Clyde married Bertha rather than Beatrice.

The contrastive focus in "Clyde married Bertha", in turn, serves to determine that the scope of the operator "knows" in (7b) is restricted to the nature of Clyde's relationship with Bertha, so that the only relevant alternatives are, say, the following:

(a4) Clyde married Bertha.

(a6) Clyde merely lived with Bertha.

This can be brought out by reformulating (7b) as:

(7b*) Alex knows that Clyde married rather than merely lived with Bertha.

It is not implausible that $\left(7 \mathrm{a}^{*}\right)$ is false while $\left(7 \mathrm{~b}^{*}\right)$ is true. It is thus not implausible that, as Dretske claims, (7a) and (7b) differ in meaning despite the fact that the embedded expressions "Clyde married Bertha" and "Clyde married Bertha" are the same in meaning.

How exactly, for Dretske, do $\left(7 \mathrm{a}^{*}\right)$ and $\left(7 \mathrm{~b}^{*}\right)$ differ in meaning? Is it that the proposition that Alex is said by $\left(7 \mathrm{a}^{*}\right)$ to know and the proposition that Alex is said by $\left(7 b^{*}\right)$ to know are different propositions? Or is it something else?

It is standardly thought that knowledge is a binary relation between a subject $\mathrm{S}$ and a proposition $\mathrm{P}$, where " $\mathrm{K}(\mathrm{S}, \mathrm{P})$ " expresses the proposition that the knowledge relation stands between $\mathrm{S}$ and $\mathrm{P}$. A natural idea, then, is that $\left(7 \mathrm{a}^{*}\right)$ and $\left(7 \mathrm{~b}^{*}\right)$ are to be understood as follows:

$\left(7 \mathrm{a}^{* *}\right) \quad \mathrm{K}($ Alex, Clyde married Bertha rather than Beatrice).

$\left(7 b^{* *}\right) \quad \mathrm{K}($ Alex, Clyde married Bertha rather than merely lived with Bertha).

These two expressions have the same first term. And although the second term in each expression is a contrastive proposition, the contrastive propositions differ. Clearly, then, if $\left(7 \mathrm{a}^{*}\right)$ and $\left(7 \mathrm{~b}^{*}\right)$ are to be read as $\left(7 \mathrm{a}^{* *}\right)$ and $\left(7 \mathrm{~b}^{* *}\right)$, it follows that $\left(7 \mathrm{a}^{*}\right)$ and $\left(7 \mathrm{~b}^{*}\right)$, and thus (7a) and (7b), differ in meaning. 
Dretske, though, denies that knowledge is a binary relation. He holds that knowledge is a ternary relation between a subject $\mathrm{S}$, a proposition $\mathrm{P}$, and a set of relevant alternatives $A$, such that $P$ is a member of $A$ and exactly one member of $A$ is true. " $K(S, P, A)$ " expresses the proposition that the knowledge relation stands between $\mathrm{S}, \mathrm{P}$, and $\mathrm{A}$. His theory of knowledge is thus an instance of what is nowadays called "a contrastivist theory of knowledge". So it is not the case that, for Dretske, $\left(7 a^{*}\right)$ and $\left(7 b^{*}\right)$ are to be understood as $\left(7 \mathrm{a}^{* *}\right)$ and $\left(7 \mathrm{~b}^{* *}\right)$.

The literature on contrastivist theories of knowledge is rapidly growing. ${ }^{21}$ And this, as we see it, all traces back to Dretske $(1970,1975,1981 b)$. The following passage (from Dretske 1970) is representative:

To know that $\mathrm{x}$ is $\mathrm{A}$ is to know that $\mathrm{x}$ is $\mathrm{A}$ within a framework of relevant alternatives, $\mathrm{B}, \mathrm{C}$, and $\mathrm{D}$. This set of contrasts, together with the fact that $\mathrm{x}$ is $\mathrm{A}$, serve to define what it is that is known when one knows that $\mathrm{x}$ is $\mathrm{A}$. One cannot change this set of contrasts without changing what a person is said to know when he is said to know that $\mathrm{x}$ is A. (p. 1022)

On our reading, then, Dretske is a contrastivist about knowledge and DSK should be understood accordingly. ${ }^{22}$

Return now to $\left(7 a^{*}\right)$ and $\left(7 b^{*}\right)$. The former should be understood as:

$\left(7 \mathrm{a}^{* * *}\right) \quad \mathrm{K}($ Alex, Clyde married Bertha, \{Clyde married Bertha, Clyde married Beatrice $\}$ ).

The latter, in turn, should be understood as:

$\left(7 b^{* * *}\right) \quad \mathrm{K}($ Alex, Clyde married Bertha, \{Clyde married Bertha, Clyde merely lived with Bertha\}).

${ }^{21}$ See Aikin (2006), Baumann (2008), Blauuw (2008a, b), Buenting (2010), Johnsen (2001), Kvanvig (2008), Morton (2013), Morton and Karjalainen (2008), Neta (2008), Pritchard (2008), Rieber (1998), Sawyer (2014, 2015), Schaffer (2005a, 2007, 2008), Sinnott-Armstrong (2004, 2008), and van Woudenberg (2008).

${ }^{22}$ It should be noted that Sawyer (2015), for one, has a different reading of Dretske's theory of knowledge. She reads it as a non-contrastivist theory on which knowledge is a binary relation — between a subject and a proposition — holding against a set of alternatives. This reading is interesting. But, unfortunately, we do not have the space to give it the attention it deserves. As we see it, this is okay, given that DSK is interesting in and of itself. It would be interesting, regardless of whether Dretske's theory of knowledge is constrastivist, if there were a way of solving PUZZLE 1 on which knowledge is contrastive. 
$\left(7 \mathrm{a}^{* * *}\right)$ and $\left(7 \mathrm{~b}^{* * *}\right)$ are the same in their first and second terms: the subject is Alex and the proposition is the non-contrastive proposition that Clyde married Bertha. Where they differ is in their third terms: they involve different sets of relevant alternatives.

Recall (from Section 1) that Dretske accepts KRE (Knowledge Requires Evidence). Dretske's view, more specifically, is that $\mathrm{K}(\mathrm{S}, \mathrm{P}, \mathrm{A})$ only if S's evidence rules out every alternative in A other than $\mathrm{P}$.

We are now in a position to set out our solution to PUZZLE 1. DSK should be understood as:

Dretske on Self-Knowledge* (DSK*): Let $\mathrm{S}$ be some subject and $\mathrm{P}$ be some proposition such that $\mathrm{S}$ thinks that $\mathrm{P}$. Then $\mathrm{S}$ knows by introspection that she thinks that $\mathrm{P}$ but does not know by introspection that she thinks that $\mathrm{P}$.

The positive side of DSK* is:

(8a) S knows by introspection that she thinks that $\mathrm{P}$.

The negative side of DSK*, in turn, is the negation of:

(8b) S knows by introspection that she thinks that $\mathrm{P}$.

The contrastive focus in "she thinks that P" serves to determine that the scope of the operator "knows" in (8a) is restricted to the content of S's thought, so that the only relevant alternatives are, say, the following:

(a7) S thinks that $P$.

(a8) S thinks that Q.

The contrastive focus in "she thinks that P", in turn, serves to determine that the scope of the operator "knows" in ( $8 \mathrm{~b})$ is restricted to the attitude that S stands in towards $\mathrm{P}$, so that the only relevant alternatives are, say, the following:

(a7) S thinks that P.

(a9) S hopes that P.

(8a) and (8b) should be understood as:

(8a*) S knows by introspection that she thinks that $\mathrm{P}$ rather than that $\mathrm{Q}$. 
$\left(8 b^{*}\right) \quad \mathrm{S}$ knows by introspection that she thinks rather than hopes that $\mathrm{P}$.

$\left(8 \mathrm{a}^{*}\right)$ and $\left(8 \mathrm{~b}^{*}\right)$, in turn, should be understood as:

$\left(8 \mathrm{a}^{* *}\right) \quad \mathrm{K}(\mathrm{S}, \mathrm{S}$ thinks that $\mathrm{P},\{\mathrm{S}$ thinks that $\mathrm{P}, \mathrm{S}$ thinks that $\mathrm{Q}\})$ by introspection.

$\left(8 \mathrm{~b}^{* *}\right) \quad \mathrm{K}(\mathrm{S}, \mathrm{S}$ thinks that $\mathrm{P},\{\mathrm{S}$ thinks that $\mathrm{P}, \mathrm{S}$ hopes that $\mathrm{P}\})$ by introspection.

These expressions are the same in their first and second terms: the subject is $\mathrm{S}$ and the proposition is the non-contrastive proposition that $\mathrm{S}$ thinks that $\mathrm{P}$. Where they differ is in their third terms: they involve different sets of relevant alternatives. There $i s$, then, a way of understanding DSK on which the knowledge affirmed by its positive side is different than the knowledge denied by its negative side.

This claim, notice, is importantly different than the claim that there is a way of understanding DSK on which the proposition $\mathrm{S}$ is said by its positive side to know by introspection is different than the proposition $\mathrm{S}$ is said by its negative side to not know by introspection. Our claim is perhaps better put as follows: there is a way of understanding DSK on which the knowledge relation affirmed by its positive side is different than the knowledge relation denied by its negative side.

PUZZLE 1 is thus solved. This is welcome news, since, as noted above (in Section 1) DSK is a potential solution to PUZZLE 2.

We turn now to a worry to the effect that DSK runs counter to the probability calculus. If this worry cannot be met, then, we take it, regardless of the fact that DSK is a potential solution to PUZZLE 2, DSK should be rejected.

\section{A worry concerning transmissibility}

Consider the thesis:

Transmissibility (T): If (a) $\mathrm{R}$ is a reason for $\mathrm{S}$ to believe that $\mathrm{P}$ and (b) $\mathrm{S}$ knows that $\mathrm{P}$ entails $\mathrm{Q}$, then $\mathrm{R}$ is a reason for $\mathrm{S}$ to believe that $\mathrm{Q}$.

Dretske rejects T. He writes:

In normal circumstances - a wine tasting party, say — one's reasons for thinking there is wine left in the bottle do not transmit to, they are not reasons for believing, what you know to be implied by this - that the liquid in the bottle is not merely colored water. Having already tasted it, you may know that it is wine and not just colored water, but the point is that your reasons for believing the one (visual) are not reasons 
for believing the other (gustatory). Colored water in the bottle would look exactly the same as the wine. (2005a, p. 15)

Let $\mathrm{R}$ be your visual experience of the bottle, $\mathrm{P}$ be the proposition that there is wine left in the bottle, and $\mathrm{Q}$ be the proposition that the liquid in the bottle is not colored water. Dretske's point can be put like this: $R$ is a reason for you to believe that $P$, you know that $\mathrm{P}$ entails $\mathrm{Q}$, and yet, contra $\mathrm{T}, \mathrm{R}$ is not a reason for you to believe that $\mathrm{Q}$, since you would have $\mathrm{R}$ if $\mathrm{Q}$ were false.

$\mathrm{T}$ is distinct from the thesis:

Closure (C): If (a) $\mathrm{S}$ knows that $\mathrm{P}$, (b) $\mathrm{S}$ knows that $\mathrm{P}$ entails $\mathrm{Q}$, and (c) on the basis of this knowledge $\mathrm{S}$ comes to believe that $\mathrm{Q}$, then $\mathrm{S}$ knows that $\mathrm{Q}$.

This is noted in effect by Dretske:

Non-transmissibility does not itself imply the failure of closure since, as our wine examples illustrates, even when S's reasons for believing P do not transmit to a known consequence, Q, it may be that S must still know Q (perhaps on the basis of other reasons) in order to know P. (2005a, p. 17)

Dretske nonetheless rejects $\mathrm{C}$ as well. He does so in part on the basis of his rejection of $\mathrm{T}^{23}$

Dretske's rejection of T, though, can seem puzzling. Suppose $\mathrm{R}$ is a reason for $\mathrm{S}$ to believe that P. Suppose $\mathrm{S}$ knows that $\mathrm{P}$ entails $\mathrm{Q}$. Given that knowledge is factive, it follows that $\mathrm{P}$ entails $\mathrm{Q}$. It is a theorem of the probability calculus that: For any $\mathrm{X}, \mathrm{Y}$, and $Z$, if $Y$ entails $Z$, then $p(Y \mid X) \leq p(Z \mid X)$. Given this, and given that $P$ entails $Q$, it follows that $\mathrm{p}(\mathrm{P} \mid \mathrm{R}) \leq \mathrm{p}(\mathrm{Q} \mid \mathrm{R}){ }^{24}$ If $\mathrm{S}$ 's credence in $\mathrm{Q}$ given $\mathrm{R}$ should be at least as high as her credence in $P$ given $R$, then how could it be that $R$ is a reason for her to believe that $\mathrm{P}$ but is not a reason for her to believe that $\mathrm{Q}$ ?

This worry about Dretske's rejection of T is related to DSK, for Dretske claims that DSK implies that $\mathrm{T}$ is false. ${ }^{25}$ If Dretske is right in this claim, and if DSK thereby runs counter to the probability calculus, then, we take it, DSK should be rejected.

Dretske, though, should not claim that DSK implies that $\mathrm{T}$ is false. Return to Dretske's contrastivism on knowledge. This is based on his contrastivism on reasons to

${ }^{23}$ See Baumann (2006), Dretske (2005a, 2005b, 2006a), Hawthorne (2005), Jager (2004), and Shackel (2006) for recent discussion of Dretske on C.

${ }^{24}$ Here it is being assumed that $\mathrm{R}$ is a proposition as opposed to an experience.

${ }^{25}$ Dretske claims this in effect in Dretske (2012a). He is more explicit in Dretske (2003a, pp. 139-140). 
believe. He holds that whether $\mathrm{R}$ is a reason for $\mathrm{S}$ to believe that $\mathrm{P}$ depends in part on the set of relevant alternatives in play. The positive side of DSK is based on the claim that:

(9a) S's o-awareness of the proposition that $\mathrm{P}$ is a reason, relative to $\mathrm{A}_{1}=\{$ she thinks that $\mathrm{P}$, she thinks that $\mathrm{Q}\}$, for $\mathrm{S}$ to believe that she thinks that $\mathrm{P}$.

The negative side of DSK, in turn, is based on the negation of the claim that:

$\mathrm{S}$ 's o-awareness of the proposition that $\mathrm{P}$ is a reason, relative to $\mathrm{A}_{2}=\{$ she thinks that $\mathrm{P}$, she hopes that $\mathrm{P}$ \}, for $\mathrm{S}$ to believe that she thinks that $\mathrm{P}$.

There is mention in (9a) and (9b) of sets of relevant alternatives. This is not the case, however, with respect to $\mathrm{T}$. Dretske should thus claim not that $\mathrm{T}$ is false but that $\mathrm{T}$ is underspecified. ${ }^{26}$

There are but two ways of fleshing out $\mathrm{T}$ in terms of Dretske's contrastivism on reasons to believe. They are:

Transmissibility* $\left(T^{*}\right)$ : If (a) $\mathrm{R}$ is a reason, relative to $\mathrm{A}$, for $\mathrm{S}$ to believe that $\mathrm{P}$ and

(b) $\mathrm{S}$ knows that $\mathrm{P}$ entails $\mathrm{Q}$, then $\mathrm{R}$ is a reason, relative to $\mathrm{A}$, for $\mathrm{S}$ to believe that $\mathrm{Q}$.

Transmissibility** ( $T^{* *}$ ): If (a) $\mathrm{R}$ is a reason, relative to $\mathrm{A}$, for $\mathrm{S}$ to believe that $\mathrm{P}$ and (b) $\mathrm{S}$ knows that $\mathrm{P}$ entails $\mathrm{Q}$, then $\mathrm{R}$ is a reason, relative to $\mathrm{A}^{*}$ (which can be but need not be identical to $\mathrm{A}$ ), for $\mathrm{S}$ to believe that $\mathrm{Q}$.

DSK is neutral on $\mathrm{T}^{*}$ but not on $\mathrm{T}^{* *}$. Suppose that DSK is correct and thus that (9a) is true whereas (9b) is false. Then, since (it can be assumed) $\mathrm{S}$ knows that the proposition that she thinks that $\mathrm{P}$ entails itself, it follows that $\mathrm{T}^{* *}$ 's antecedent holds but its consequent does not. Hence $\mathrm{T}^{* *}$ is false.

It is true, then, that DSK implies the falsity of a certain transmissibility thesis. Does DSK thereby run counter to the probability calculus?

The answer is negative. The probabilities to consider when evaluating (9a) and (9b) are:

(9a*) $\quad \mathrm{p}(\mathrm{S}$ thinks that $\mathrm{P} \mid \mathrm{S}$ is o-aware of the proposition that $\mathrm{P}$ and [either $\mathrm{S}$ thinks that $\mathrm{P}$ or $\mathrm{S}$ thinks that $\mathrm{Q}$ (but not both)])

\footnotetext{
${ }^{26}$ Something similar is true with respect to C. Given Dretske's contrastivism on knowledge, and given that there is no mention in $\mathrm{C}$ of any sets of relevant alternatives, his view should be not that $\mathrm{C}$ is false but that $\mathrm{C}$ is underspecified.
} 
(9b*) $\quad \mathrm{p}(\mathrm{S}$ thinks that $\mathrm{P} \mid \mathrm{S}$ is o-aware of the proposition that $\mathrm{P}$ and [either $\mathrm{S}$ thinks that $\mathrm{P}$ or $\mathrm{S}$ hopes that $\mathrm{P}$ (but not both)])

These probabilities have different givens: the second conjunct of the given in ( $\left.9 a^{*}\right)$ is a disjunction of the alternatives in $A_{1}$, whereas the second conjunct of the given in $\left(9 b^{*}\right)$ is a disjunction of the alternatives in $\mathrm{A}_{2} \cdot{ }^{27}$ So nothing in the probability calculus precludes Dretske from claiming that $\left(9 \mathrm{a}^{*}\right)=1>\left(9 \mathrm{~b}^{*}\right)$ and that, because of this, (9a) is true whereas $(9 b)$ is false.

It might be that Dretske's contrastivism on reasons to believe is mistaken. But that is another matter. The important point for our purposes is that DSK does not run counter to the probability calculus.

\section{Conclusion}

DSK is interesting and potentially very important insofar as it is meant to solve PUZZLE 2 and thereby show how IK, KRE, and NIE can all be true. At the same time, however, there are some worries. First, there is the worry that PUZZLE 1 admits of no satisfactory solution, that is, that there is no satisfactory way of understanding DSK on which the introspective knowledge affirmed by its positive side is different than the introspective knowledge denied by its negative side. Second, there is the worry that DSK runs counter to $\mathrm{T}$ and thereby runs counter to the probability calculus. These are serious worries. But each of them, we have argued, can be adequately answered.

A number of issues remain. We will close by noting two. First, DSK must be evaluated on its own terms. For example, whether an o-awareness of a proposition, as opposed to an o-awareness of a concrete object, can serve as a reason for a contingent proposition must be investigated. Second, DSK, being a form of contrastivism about knowledge, is perhaps relevant to the growing debate in epistemology on the viability of contrastivism. Its potential relevance should be explored.

\section{References}

Aikin, S. (2006). Contrastive self-attribution of belief. Social Epistemology, 20, 93-103. Aydede, M. (2003). Is introspection inferential? In B. Gertler (Ed.), Privileged access: Philosophical accounts of self-knowledge (pp. 55-64). Burlington: Ashgate.

${ }^{27}$ Relevant here is the point from Section 2 that the difference in contrastive focus between (6a) and (6b) can be captured in terms of the expression "Given that (or on the understanding that)". 
Baumann, P. (2006). Information, closure, and knowledge: On Jager's objection to Dretske. Erkenntnis, 64, 403-408.

Baumann, P. (2008). Contrastivism rather than something else? On the limits of epistemic contrastivism. Erkenntnis, 69, 189-200.

Blaauw, M. (2008a). Contesting Pyrrhonian contrastivism. Philosophical Quarterly, 58, 471-477.

Blaauw, M. (2008b). Contrastivism in epistemology. Social Epistemology, 22, 227-234.

Buenting, J. (2010). An epistemic reduction of contrastive knowledge claims. Social Epistemology, 24, 99-104.

Byrne, A. (2012). Knowing what I see. In D. Smithies and D. Stoljar (Eds.), Introspection and consciousness (pp. 183-209). Oxford: Oxford University Press.

Dretske, F. (1969). Seeing and knowing. Chicago: University of Chicago Press.

Dretske, F. (1970). Epistemic operators. Journal of Philosophy, 67, 1007-1023.

Dretske, F. (1971). Conclusive reasons. Australasian Journal of Philosophy, 49, 1-22.

Dretske, F. (1972). Contrastive statements. Philosophical Review, 81, 411-437.

Dretske, F. (1975). The content of knowledge. In B. Freed, A. Marras, and P. Maynard (Eds.), Forms of representation (pp. 77-93). Amsterdam: North-Holland.

Dretske, F. (1977). Referring to events. Midwest Studies in Philosophy, 2, 90-99.

Dretske, F. (1981a). Knowledge and the flow of information. Cambridge MA: MIT Press.

Dretske, F. (1981b). The pragmatic dimension of knowledge. Philosophical Studies, 40, 363-378.

Dretske, F. (1991). Dretske's replies. In B. McLaughlin (Ed.), Dretske and his critics (pp. 180-221). Cambridge MA: Basil Blackwell.

Dretske, F. (1994). Introspection. Proceeding of the Aristotelian Society, 94, 263-278.

Dretske, F. (1995). Naturalizing the mind. Cambridge MA: MIT Press.

Dretske, F. (1999). The mind's awareness of itself. Philosophical Studies, 95, 103-124.

Dretske, F. (2003a). Externalism and self-knowledge. In S. Nuccetelli (Ed.), New essays on semantic externalism and self-knowledge (pp. 131-142). Cambridge MA: MIT Press.

Dretske, F. (2003b). How do you know you are not a zombie? In B. Gertler (Ed.), Privileged access: Philosophical accounts of self-knowledge (pp. 1-13). Burlington: Ashgate.

Dretske, F. (2003c). Knowing what you think vs. knowing that you think. In R. Schantz (Ed.), The externalist challenge: New studies on cognition and intentionality (pp. 389-400). Berlin: Walter de Gruyter.

Dretske, F. (2005a). The case against closure. In M. Steup and E. Sosa (Eds.), Contemporary debates in epistemology (pp. 13-26). Malden: Blackwell.

Dretske, F. (2005b). Reply to Hawthorne. In M. Steup and E. Sosa (Eds.), Contemporary debates in epistemology (pp. 43-46). Malden: Blackwell.

Dretske, F. (2006a). Information and closure. Erkenntnis, 64, 409-413. 
Dretske, F. (2006b). Representation, teleosemantics, and the problem of self-knowledge. In G. Macdonald and D. Papineau (Eds.), Teleosemantics (pp. 69-84). NY: Oxford University Press.

Dretske, F. (2011). Skeptical doubts about self-knowledge. In S. Bernecker and D. Pritchard (Eds.), The Routledge companion to epistemology (pp. 425-432). NY: Routledge.

Dretske, F. (2012a). Awareness and authority: Skeptical doubts about self-knowledge. In D. Smithies and D. Stoljar (Eds.), Introspection and consciousness (pp. 49-64). Oxford: Oxford University Press.

Dretske, F. (2012b). Doubts about cogito. Grazer Philosophische Studien, 84, 1-17.

Dretske, F. (2012c). I think I think, therefore I am - I think: Skeptical doubts about selfknowledge. In J. Liu and J. Perry (Eds.), Consciousness and the self: New essays (pp. 150-164). NY: Cambridge University Press.

Gertler, B. (2014). Self-knowledge. In E. Zalta (Ed.), Stanford Encyclopedia of Philosophy. URL $=<$ http://plato.stanford.edu/archives/win2014/entries/selfknowledge/>.

Hawthorne, J. (2005). The case for closure. In M. Steup and E. Sosa (Eds.), Contemporary debates in epistemology (pp. 26-43). Malden: Blackwell.

Jager, C. (2004). Skepticism, information, and closure: Dretske's theory of knowledge. Erkenntnis, 61, 187-201.

Johnsen, B. (2001). Contextualist swords, skeptical plowshares. Philosophy and Phenomenological Research, 62, 385-406.

Kemmerling, A. (1999). How self-knowledge can't be naturalized (some remarks on a proposal by Dretske). Philosophical Studies, 95, 311-328.

Kvanvig, J. (2008). Contrastivism and closure. Social Epistemology, 22, 247-256.

Lau, J., and Deutsch, M. (2014). Externalism about mental content. In E. Zalta (Ed.), Stanford Encyclopedia of Philosophy. URL $=$

$<$ http://plato.stanford.edu/archives/sum2014/entries/content-externalism/>.

Lycan, W. (1999). Dretske on the mind's awareness of itself. Philosophical Studies, 95, 125-133.

Lycan, W. (2003). Dretske's ways of introspecting. In B. Gertler (Ed.), Privileged access: Philosophical accounts of self-knowledge (pp. 15-29). Burlington: Ashgate.

Morton, A. (2013). Contrastive knowledge. In M. Blaauw (Ed.), Contrastivism in philosophy (pp. 101-115). New York: Routledge.

Morton, A., and Karjalainen, A. (2008). Contrastivity and indistinguishability. Social Epistemology, 22, 271-280.

Neta, R. (2008). Undermining the case for contrastivism. Social Epistemology, 22, 289304. 
Parent, T. (2013). Externalism and self-knowledge. In E. Zalta (Ed.), Stanford Encyclopedia of Philosophy. URL = $<$ http://plato.stanford.edu/archives/sum2013/entries/self-knowledge-externalism/>.

Pritchard, D. (2008). Contrastivism, evidence, and scepticism. Social Epistemology, 22, 303-323.

Rieber, S. (1998). Skepticism and contrastive explanation. Nous, 32, 189-204.

Roche, M., and Roche, W. (2016). Review of Declan Smithies and Daniel Stoljar's (Eds.) Introspection and consciousness (2012, Oxford University Press). Philosophical Quarterly, 66, 203-208.

Sawyer, S. (2014). Contrastive self-knowledge. Social Epistemology, 28, 139-152.

Sawyer, S. (2015). Contrastive self-knowledge and the McKinsey paradox. In S. Goldberg (Ed.), Externalism, self-knowledge, and skepticism: New essays (pp. 75-93). Cambridge: Cambridge University Press.

Schaffer, J. (2005a). Contrastive knowledge. In T. Gendler and J. Hawthorne (Eds.), Oxford studies in epistemology: Volume 1 (pp. 235-271). Oxford: Oxford University Press.

Schaffer, J. (2005b). Contrastive causation. Philosophical Review, 114, 327-358.

Schaffer, J. (2007). Closure, contrast, and answer. Philosophical Studies, 133, 233-255.

Schaffer, J. (2008). The contrast-sensitivity of knowledge ascriptions. Social Epistemology, 22, 235-245.

Schwitzgebel, E. (2014). Introspection. In E. Zalta (Ed.), Stanford Encyclopedia of Philosophy. URL = $<$ http://plato.stanford.edu/archives/sum2014/entries/introspection/>.

Shackel, N. (2006). Shutting Dretske's door. Erkenntnis, 64, 393-401.

Shoemaker, S. (1994). Self-knowledge and "inner sense". Philosophy and Phenomenological Research, 54, 249-314.

Sinnott-Armstrong, W. (2004). Classy Pyrrhonism. In W. Sinnott-Armstrong (Ed.), Pyrrhonian skepticism (pp. 188-207). Oxford: Oxford University Press.

Sinnott-Armstrong, W. (2008). A contrastivist manifesto. Social Epistemology, 22, 257270.

Smithies, D., and Stoljar, D. (Eds.) (2012). Introspection and consciousness. Oxford: Oxford University Press.

Stoljar, D. (2012). Knowledge of perception. In D. Smithies and D. Stoljar (Eds.), Introspection and consciousness (pp. 65-89). Oxford: Oxford University Press.

van Woudenberg, R. (2008). The knowledge relation: Binary or ternary? Social Epistemology, 22, 281-288. 